\title{
First case of Arthrographis kalrae pulmonary infection in a patient with AIDS
}

\author{
Neha Samal, M.V. Narasimham, Susmita Kumari Sahu, Sanghamitra Padhi \\ Department of Microbiology, Maharaja Krishna Chandra Gajapati Medical College and Hospital (MKCG), Ganjam, \\ Odisha, India
}

\begin{abstract}
Summary
Arthrographis kalrae is a hyaline fungus. It is a saprophyte of the environment, mainly found in soil and compost. It is a rare isolate in clinical specimen. In recent years this pathogen has been attributed to various cases of opportunistic infections. Our patient was a 51-year-old Indian woman, farmer by occupation, who had HIV infection and was under HAART treatment. She presented with complaints of cough with scanty expectoration for 2 months. Her $\mathrm{CD}_{4}$ count was 75 cells $/ \mu 1$. Induced sputum was collected and sent for detailed microbiological examination. Bacteriological and mycological profile was checked. The causal agent was identified as Arthrographis kalrae based on morphological characteristics (culture). Unfortunately, samples could not be preserved and sent for ITS region sequencing due to COVID-19 outbreak. The case is of interest because, to the best of our knowledge, Arthrographis kalrae has not been reported so far from our country, India.
\end{abstract}

\section{Introduction}

The human immunodeficiency virus (HIV) causes the acquired immunodeficiency syndrome (AIDS) which is the most

Correspondence: M.V. Narasimham, Department of Microbiology, Maharaja Krishna Chandra Gajapati Medical College and Hospital (MKCG), Ganjam, Odisha, India.

E-mail: mayur9.praraj@gmail.com

Key words: Arthrographis kalrae, pulmonary infection, AIDS.

Contributions: The authors contributed equally.

Conflict of interest: The authors declare no potential conflict of interest.

Funding: None.

Received for publication: 16 February 2021.

Revision received: 3 March 2021.

Accepted for publication: 3 March 2021.

${ }^{\circ}$ Copyright: the Author(s), 2021

Licensee PAGEPress, Italy

Microbiologia Medica 2021; 36:9684

doi:10.4081/mm.2021.9684

This article is distributed under the terms of the Creative Commons Attribution Noncommercial License (by-nc 4.0) which permits any noncommercial use, distribution, and reproduction in any medium, provided the original author(s) and source are credited. important public health problem of the $20^{\text {th }}$ century. A decline in the $\mathrm{CD}_{4}$ count among PLHA makes patients prone to various opportunistic infections, $70 \%$ of which accounts for respiratory infections. A variety of bacteria, yeasts and filamentous fungi has been recovered from the respiratory samples in the HIV infected patients. Fungal pneumonias are often overlooked and underdiagnosed, even though they are an important bulk of opportunistic mycoses in HIV reactive patients. The relevance of fungi in causing opportunistic pneumonia can be further highlighted by the fact that it was the opportunistic fungus Pneumocystis carinii (now Pneumocystis jiroveci) that heralded the discovery of HIV/AIDS, when reports of pneumonia caused by this agent in previously healthy men, who had sex with other men and/or who were injection drug users, first appeared in 1981 in the United States of America.

Here we report a case of a fungal pulmonary infection by a rare fungus, Arthrographis kalrae (A. kalrae) in a HIV infected female patient with low $\mathrm{CD}_{4}$ count, which was isolated from her induced sputum and identified by phenotypic and microscopic characteristics. To the best of our knowledge, this is the first report of lower respiratory tract infection caused by $A$. kalrae in India.

\section{Case Description}

Our patient was a 51-year-old woman, farmer by occupation, with AIDS $\left(\mathrm{CD}_{4}\right.$ T-cell count, 75 cells/ $\left.\mu \mathrm{l}\right)$ human immunodeficiency virus (HIV) type 1 (HIV-1) who was receiving highly active antiretroviral therapy. She referred to our hospital, with main complaints of cough with canty expectoration for 2 months. She reported no history of fever or dyspnoea. As pulmonary tuberculosis is the most common co-infection seen with HIV/AIDS, she was sent from the ART Centre to the Cartridge based nucleic acid amplification test (CBNAAT) site, for detection of Mycobacterium tuberculosis. However, CBNAAT produced a negative report. In order to collect more suitable sputum, induced sputum sample was obtained. Following universally recognized precautions, the patient was instructed to clean her mouth thoroughly and inhale a solution of $3 \%$ saline in water via an ultrasonic nebuliser; then, the induced sputum was collected in a sterile container and sent to the microbiology laboratory.

\section{Procedure and observations}

In the microbiology laboratory, a detailed evaluation was performed. Initially Bartlett's scoring system was used for microscopic evaluation of the expectorated sputum to check its quality. Then, Gram staining, Ziehl Neelsen (ZN) staining, Modified Toluidine-Blue $\mathrm{O}$ staining and $\mathrm{KOH}$ mount were performed. Gram staining revealed the presence of pus cells, but no bacteria or budding yeast were detected. ZN staining was done to rule out 
the presence of any atypical mycobacteria, and it was negative. Modified Toluidine-Blue $\mathrm{O}$ staining was performed to detect the presence of any cysts of Pneumocystis jiroveci, but there were none; $10 \% \mathrm{KOH}$ mount revealed the presence of few hyaline hyphae. Furthermore, the sample was cultured on Blood agar plate, Chocolate agar plate, MacConkey agar plate, Pleuro-pneumonia like organism (PPLO) enrichment broth and 4 sets of Sabouraud's Dextrose agar with chloramphenicol $(0.05 \mathrm{mg} / \mathrm{ml})$ (SDA) tubes. Four sets of SDAs were used as two sets were kept at $25^{\circ} \mathrm{C}$ (identification of moulds) and two sets at $37^{\circ} \mathrm{C}$ (identification of yeasts). Duplicate tubes were used to confirm isolation of the same pathogen from all cultures. Blood and Chocolate agar plates were incubated in candle jar $\left(5-10 \% \mathrm{CO}_{2}\right)$ at $37^{\circ} \mathrm{C}$ and MacConkey agar plate in incubator at $37^{\circ} \mathrm{C}$ overnight. As no growth was seen in all the plates, they were re-incubated for another 24 hours. PPLO enrichment broth showed no change in its colour, indicating the absence of Mycoplasma species. The SDA tubes were examined once in two days for the $1^{\text {st }}$ week. On the $4^{\text {th }}$ day of inoculation few creamy moist colonies were seen on the SDA tube kept at $37^{\circ} \mathrm{C}$, but no growth was detected on the SDA tubes kept at $25^{\circ} \mathrm{C}$. On the $6^{\text {th }}$ day growth was seen in both tubes, kept at $25^{\circ} \mathrm{C}$ and $37^{\circ} \mathrm{C}$, respectively (Figure 1). On microscopic observation, elongated oval budding yeast cells were seen. Colonies were also sub-cultured on SDA plates containing cycloheximide $(0.4 \mathrm{gm} / \mathrm{ml})$ and kept at $37^{\circ} \mathrm{C}$. The fungus was resistant to cycloheximide and creamy colonies were seen. The colonies were initially cream coloured and glabrous, but by the $10^{\text {th }}$ day they became dry, flat, granular and then velvety (Figure 2). Slide culture was performed on Potato Dextrose agar at $25^{\circ} \mathrm{C}$. The same growth pattern was seen. Microscopically, the isolate produced hyaline septate hyphae and conidiophores were sometimes in bundles, either unbranched or branched in tree like fashion in slide culture preparations stained with Lacto-Phenol Cotton Blue (Figure 3). They produced chains of consecutive smooth-walled arthroconidia that were mostly rectangular (2-3 by 4-6 $\mu \mathrm{m})$; some were oval. Intercalary arthroconidia were also seen. Fungi in which arthroconidia predominate are

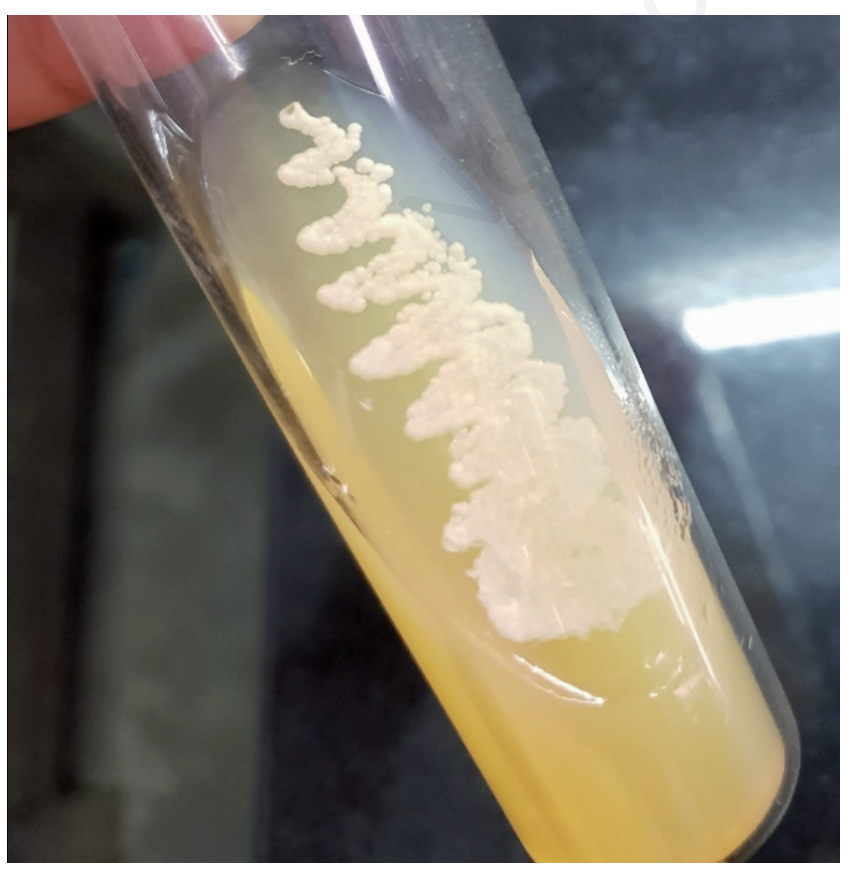

Figure 1. Smooth yeastlike moist colonies of Arthrographis kalrae. from genus Geotrichum, Trichosporon, Geomyces, Malabranchea, Arthrographis and Coccidiodes. Conidiophores are only present in genus Arthrographis and Geomyces, so others were ruled out. As genus Geomyces has barrel-shaped and alternating arthroconidia, it was also excluded. On the basis of the characteristics presented above, the isolate was identified to belong to the genus Arthrographis. It consists of five species: A. kalrae, A. cuboidea,

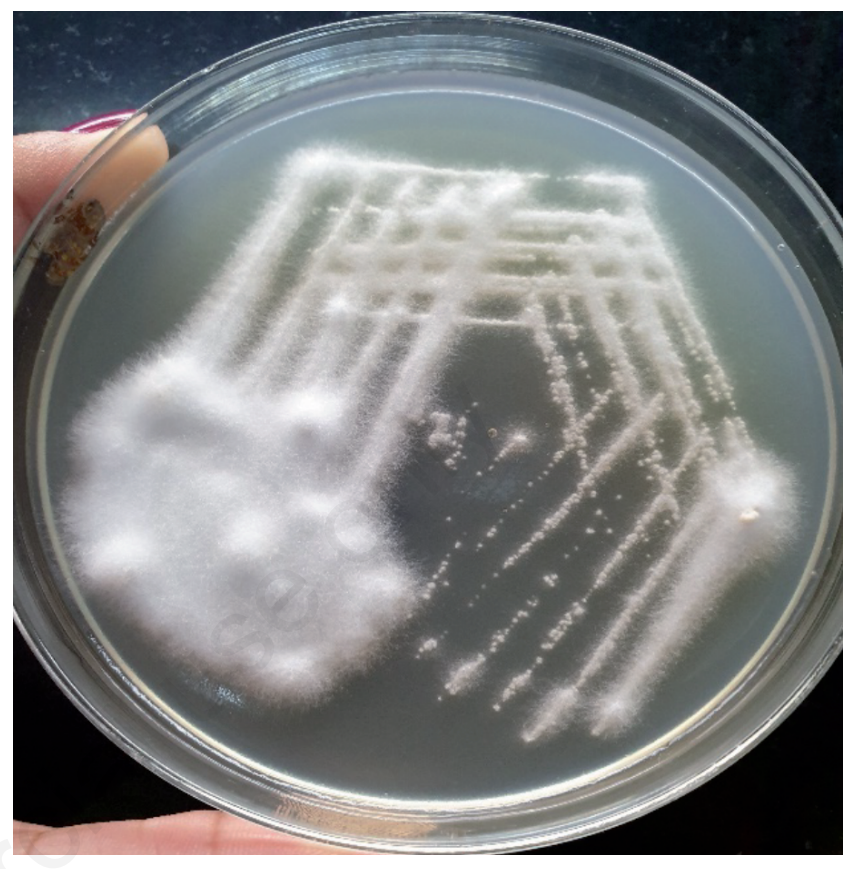

Figure 2. Velvety colonies of Arthrographis kalrae after 10 days of incubation.

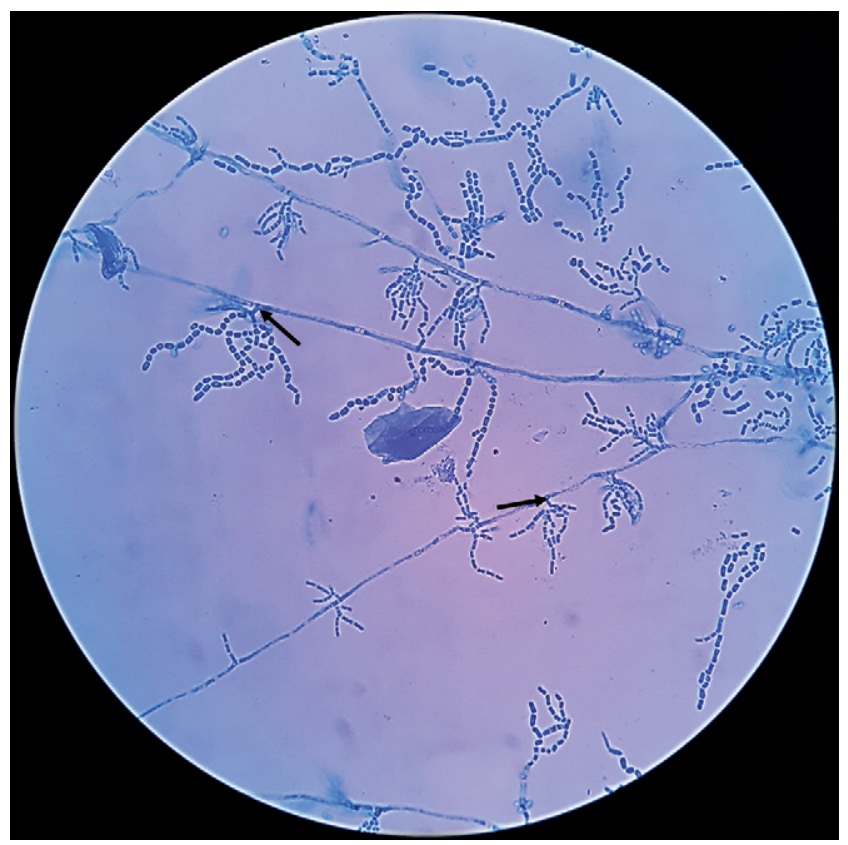

Figure 3. Arthroraphis kalrae. A slide culture was stained with Lacto-Phenol Cotton Blue. Black arrow: conidiophore. 
Table 1. Characteristics of previously published cases of infection with Arthrographis kalrae.

\begin{tabular}{|c|c|c|c|c|c|}
\hline \multicolumn{2}{|c|}{ ReferenceAge (yrs) } & \multirow{2}{*}{$\begin{array}{l}\text { Sex } \\
\text { F }\end{array}$} & \multirow{2}{*}{$\begin{array}{l}\text { Country } \\
\text { France }\end{array}$} & \multirow{2}{*}{$\begin{array}{l}\text { Pathology } \\
\text { Cystic fibrosis }\end{array}$} & \multirow{2}{*}{$\begin{array}{l}\text { Risk factor } \\
\text { Malnutrition }\end{array}$} \\
\hline 12 & 19 & & & & \\
\hline 1 & 63 & $\mathrm{H}$ & Japan & Onychomycosis & ND \\
\hline 2 & ND & ND & Slovakia & Onychomycosis & ND \\
\hline 3 & 80 & $\mathrm{H}$ & France & Mycetoma & Systemic corticosteroid \\
\hline 5 & 42 & $\mathrm{~F}$ & Germany & Keratitis & Soft lens wearer \\
\hline 6 & 52 & $\mathrm{H}$ & Malaysia & Keratitis & Injury \\
\hline 7 & 39 & M & China & Keratitis and sinusitis & Injury \\
\hline 8 & 23 & $\mathrm{~F}$ & USA & Keratitis & Soft lens wearer \\
\hline 9 & 33 & $\mathrm{H}$ & Australia & Knee joint infection & Injury \\
\hline 10 & ND & $\mathrm{H}$ & Italy & Knee joint infection & Injury \\
\hline 11 & 50 & $\mathrm{~F}$ & Spain & Endocarditis & Pericardial patch \\
\hline 13 & 61 & $\mathrm{H}$ & Netherlands & Pulmonary infection & Radiotherapy \\
\hline 15 & 33 & $\mathrm{H}$ & USA & Meningitis and sinusitis & AIDS \\
\hline 16 & 39 & M & France & Fungal stroke & Malnutrition \\
\hline
\end{tabular}

A. lignicola, A. pinicola and A. alba. Among them, A. alba fails to grow at $37^{\circ} \mathrm{C}$ and $A$. pinicola fails to grow on media containing cycloheximide; therefore, they were both ruled out. A. cuboidea was distinguished as it is a fast grower and colony matures within 4-5 days; however, in our case a full maturation of the isolated fungi took around 15-20 days. A. lignicola was ruled-out as it has broad yellow arthroconidia. Therefore, on the basic of morphological and growth characteristics, the isolated fungi were determined to be Arthrographis kalrae.

\section{Discussion}

A. kalrae is an uncommon human pathogen commonly found in soil and compost. There has been a rise in the cases of Arthrographis infection in the past years. As per 2016 data, one case of infection with Arthrographis species and 15 cases of infection with $A$. kalrae have been reported: two onychomycosis $(1,2)$, one mycetoma (3), five keratitis (4-8), one of which associated with sinusitis (7), two knee joint infection $(9,10)$, one endocarditis (11), three pulmonary infections (12-14), one meningitis (15) and one fungal stroke (16)(Table 1). These cases have a worldwide distribution: eight cases in Europe, one in China, one in Japan, three in USA, one in Mexico, one in Malaysia and one in Australia. Ours is the first case identified in India. Three of the five patients with keratitis were soft contact lens wearers; the other two with knee joint infections have had an injury contaminated with soil. The rest of the patients had predisposing infection factors, such as malnutrition, systemic corticosteroids, radiotherapy, AIDS, allogeneic hematopoietic stem cell transplant (12). In our case also the patient was immunocompromised with a low CD4 count of 75 cells $/ \mu 1$. Furthermore, as she was a farmer, was probably exposed to the fungus while working in fields. Sugiura et al. also showed similar findings in Japan.

Diagnoses were always based on phenotypic characteristics and microscopic morphology using de Hoog and Sigler and Carmichael descriptions $(17,18)$. In most cases, identification of the species was confirmed by molecular biology techniques (ITS, D1/D2 sequencing) (12). Our study, in a resource limited setting, has used detailed morphological and cultural characteristics to evaluate the sample and reach its diagnosis (genus level identifica- tion and species level identification)(12,19). Furthermore, the samples were preserved for ITS sequencing but unfortunately, due to the tragic pandemic of COVID-19, it was not possible to subculture the isolate. Antifungal susceptibility was not possible in our case study. Moreover, the patient's follow up was also lost.

\section{Limitation of study}

Due to COVID-19 pandemic it was very difficult to sub-culture this rare pathogen, perform its antifungal susceptibility testing and send it to the laboratory for ITS region sequencing.

\section{Conclusions}

In immunocompromised patients, a variety of opportunistic infections can take place. Therefore, in the presence of immune suppression, malignancy, chronic illness and other risk factors among patients, a careful evaluation of clinical samples is always necessary as it will help clinicians to better treat the patients. Low CD4 count also plays a key role in increasing opportunistic infections in HIV patients.

In conclusion, we report the first case of a pulmonary infection caused by A.kalrae. This case illustrates that HIV infected patients are susceptible to opportunistic infections with uncommon pathogens.

\section{References}

1. Sugiura Y, Hironaga M. Arthrographis kalrae, a rare causal agent of onychomycosis, and its occurrence in natural and commercially available soils. Med Mycol 2010;48:384-9.

2. Volleková A, Lisalová M, Poczová M. Arthrographis kalrae an uncommon causative agent of onychomycosis. Epidemiol Mikrobiol Imunol Cas Spolecnosti Epidemiol Mikrobiol Ceské Lékarské Spolecnosti JE Purkyne. 2008;57:53.6.

3. Degavre B, Joujoux JM, Dandurand M, Guillot B. First report of mycetoma caused by Arthrographis kalrae: successful treatment with itraconazole. J Am Acad Dermatol 1997;37:318-20. 
4. Biser SA, Perry HD, Donnenfeld ED, et al. Arthrographis keratitis mimicking acanthamoeba keratitis. Cornea 2004;23:314-7.

5. Thomas BC, Zimmermann S, Völcker HE, et al. Severe Arthrographis kalrae keratomycosis in an immunocompetent patient. Cornea 2011;30:364-6.

6. Ramli SR, Francis AL, Yusof Y, Khaithir TMN. A Severe Case of Arthrographis kalrae Keratomycosis. Case Rep Infect Dis 2013;851875.

7. Xi L, Fukushima K, Lu C, et al. First case of Arthrographis kalrae ethmoid sinusitis and ophthalmitis in the People's Republic of China. J Clin Microbiol 2004;42:4828-31.

8. Perlman EM, Binns L. Intense photophobia caused by Arthrographis kalrae in a contact lens-wearing patient. Am J Ophthalmol 1997;123:547-9.

9. Boan P, Arthur I, Golledge C, Ellis D. Refractory Arthrographis kalrae native knee joint infection. Med Mycol Case Rep 2012;1:112-4.

10. Sainaghi PP, Rossati A, Buccheri C, et al. Arthrographis kalrae arthritis: a new case report. Infez Med Riv Period Eziologia Epidemiol Diagn Clin Ter Delle Patol Infett 2015;23:192-4.

11. De Diego Candela J, Forteza A, García D, et al. Endocarditis caused by Arthrographis kalrae. Ann Thorac Surg 2010;90:e4-5.

12. Julie D, Marcela S, Tristan D, et al. First case of Arthrographis kalrae fungemia in a patient with cystic fibrosis. Med Mycol Case Rep 2016;14:8-11.
13. Vos CG, Murk JL, Hartemink KJ, et al. A rare pulmonary infection caused by Arthrographis kalrae. J Med Microbiol 2012;61:593-5.

14. Corzo-León DE, Satlin MJ, Soave R, et al. Epidemiology and outcomes of invasive fungal infections in allogeneic haematopoietic stem cell transplant recipients in the era of antifungal prophylaxis: a single-centre study with focus on emerging pathogens. Mycoses 2015;58:325-36.

15. Chin-Hong PV, Sutton DA, Roemer M, et al. Invasive fungal sinusitis and meningitis due to Arthrographis kalrae in a patient with AIDS. J Clin Microbiol 2001;39:804-7.

16. Pichon N, Ajzenberg D, Desnos-Ollivier M, et al. Fatal-stroke syndrome revealing fungal cerebral vasculitis due to Arthrographis kalrae in an immunocompetent patient. J Clin Microbiol 2008;46:3152-5.

17. De Hoog GS, Guarro J, Gené J, Figueras MJ. Centraalbureau voor Schimmelcultures, Utrecht, The Netherlands, 2000. Atlas of clinical fungi, 2 nd ed.

18. Sigler L, Carmichael JW. Taxonomy of Malbranchea and some other Hyphomycetes with arthroconidia. Mycotaxon 1976;4:349-488.

19. Walsh TJ, Hayden RT, Larone DH. Larone's Medically Important Fungi. 6th ed. Washington DC: ASM Press; 2018. pp. 288,291 . 